\title{
AIAA 2002-1265 Solar Sail Loads, Dynamics, and Membrane Studies
}

K. N. Slade and W. K. Belvin

NASA Langley Research Center

Hampton, VA

V. Behun

Swales Aerospace

Hampton, VA

\section{3rd AIAAJASME/ASCE/AHS/ASC Conference on Structures, Structural Dynamics, and Materials Gossamer Spacecraft Forum 22-25 April 2002 Denver, Colorado}




\title{
SOLAR SAIL LOADS, DYNAMICS, AND MEMBRANE STUDIES
}

\author{
K. N. Slade and W. K. Belvin" \\ Structural Dynamics Branch \\ NASA Langley Research Center \\ Hampton, VA 23681
}

\author{
V. Behun \\ Swales Aerospace \\ Hampton, VA 23681
}

\begin{abstract}
While a number of solar sail missions have been proposed recently, these missions have not been selected for flight validation. Although the reasons for non-selection are varied, principal among them is the lack of subsystem integration and ground testing. This paper presents some early results from a large-scale ground testing program for integrated solar sail systems. In this series of tests, a 10 meter solar sail testbed is subjected to dynamic excitation both in ambient atmospheric and vacuum conditions. Laser vibrometry is used to determine resonant frequencies and deformation shapes. The results include some low-order sail modes which only can be seen in vacuum, pointing to the necessity of testing in that environment.
\end{abstract}

\section{Introduction}

In recent years, numerous solar sail missions and solar sail designs have been proposed (Ref. 1-3) In addition, various proposals for space flight validation of the deployment and navigation have been offered, see for example (Ref. 4). To date NASA has not selected solar sails for flight validation.

While the reasons for non-selection are varied, principal among them is the lack of subsystem integration and ground testing. Figure 1 shows

\footnotetext{
Research Engineer, Structural Dynamics Branch; Member AIAA

- Lead, Resilient Materials and Structures; Senior Member AIAA

Senior Member AIAA

Copyright 2001 by the American Institute of Aeronautics and Astronautics, Inc. No copyright is asserted in the United States under Title 17, U.S. Code. The U.S. Government has a royaltyfree license to exercise all rights under the copyright claimed herein for Governmental purposes. All other rights are reserved by the copyright owner.
}

that the path to flight validation entails a progressive advancement of technology readiness levels (TRL) from component to subsystem and system level development. Integration of component technologies at the subsystem and system level often identify opportunities to improve the components so they perform better at the system level. Advances in materials and structural components have enabled the solar sail areal density requirements $\left(\sim 10 \mathrm{~g} / \mathrm{m}^{2}\right)$ to be realized. For example, thin film materials such as CP1 (Ref. 5) now provide large area space-durable films of less than $7 \mathrm{~g} / \mathrm{m}^{2}$ areal density $(<5 \mathrm{~mm}$ in thickness). Solar sail booms utilizing either inflation, strain energy, or shape memory for deployment and rigidization via appropriate resin systems have achieved less than $50 \mathrm{~g} / \mathrm{m}$ linear density (Ref 6) The component technologies are at TRL $3+$, tested in extensively in laboratory settings.

\begin{tabular}{|c|c|c|}
\hline $\begin{array}{l}\text { Component } \\
\text { Technology }\end{array}$ & Subsystem/System & Integration and Test \\
\hline $\begin{array}{l}\text { - Structurat design tools } \\
\text {-Thin film and } \\
\text { ngidzable materials } \\
\text { and databases } \\
\text {-RigidrablerDeployable } \\
\text { structures and } \\
\text { detabeses } \\
\text {-Membrane structure } \\
\text { peckaging, tensioning } \\
\text { and deployment control } \\
\text {-Multifunction and } \\
\text { adaptive components } \\
\text { TRL 1-3 }\end{array}$ & $\begin{array}{l}\text { Ground } \\
\text { Experiments } \\
\text { Membrane-Column } \\
\text { interiace and tensioning } \\
\text { tVlembrane packaxing. } \\
\text { ascent venting, and } \\
\text { deployment contro } \\
\text {-Static shape (planarity, } \\
\text { wrnkling, etc.) } \\
\text {-Dynamic response } \\
\text { measurement and } \\
\text { correlation wh anaksis } \\
\text { TRL 4-5 }\end{array}$ & $\begin{array}{l}\text { Fllght Experiments } \\
\text { - Mlicia-urity } \\
\text { depluyment } \\
\text { - Steering cuntrol } \\
\text { subsystem tests } \\
\text { - Static shape (planarity } \\
\text { wrinking, etc) } \\
\text { - Dynamic response } \\
\text { measurement and } \\
\text { correlation with anaysis } \\
\text {-Seal GN\&C tests } \\
\text { TRL 6-8 }\end{array}$ \\
\hline
\end{tabular}

Figure 1. Solar Sail Technology Development Process

Subsystem integration of the materials and structures components into prototype solar sail 
models for ground testing is the next step in advancing sail technology readiness.

Unfortunately, a systematic effort to integrate the component technologies into solar sail ground testbeds has not received adequate attention. Ground testing of solar sail models to measure deployment loads, static shape and dynamic response is difficult due to gravity induced deformations, minimum gage designs that limit scaling, and the need for non-intrusive measurement systems

The most relevant efforts to the present study are the deployed $20 \mathrm{~m}$ by $20 \mathrm{~m}$ square sail (Ref. 7 ) and the deployed scaled sunshield (Ref. 8). Both of these deployments were in ambient atmosphere. Goddard Space Flight Center performed dynamic testing in vacuum of a subscale sunshield (Ref. 9) which greatly advanced the technology readiness of the sunshield design and analyses.

The NASA Langley Research Center (LaRC) has undertaken an effort to provide the ground test methods for solar sail testbeds. The goal is to provide static and dynamic response measurements of geometrically scaled models that can be used to validate the structural analysis and design tools used for flight mission design. The effort will leverage the numerous component technology activities already underway to provide sail booms, thin film membranes, and interface technology components. The ground test methods and analysis correlation approaches will then be adapted for flight experiments.

To this end, the present paper presents early results from a 10 meter square sail ground testbed. The square, four-quadrant architecture shown in Fig. 2 was selected for initial study. The first testbed consists of only two quadrants and one boom such that subsystem integration and test methodologies could be developed with minimal hardware costs. The component technologies (booms and sail membranes) in this initial testbed are not meant to represent the stateof-the-art. Several vendors will provide high quality testbed components in the near future. The results herein are to indicate a viable approach to the measurement of static shape and dynamic response and to illustrate the challenges posed by ground testing of ultra-lightweight structures such as solar sails.

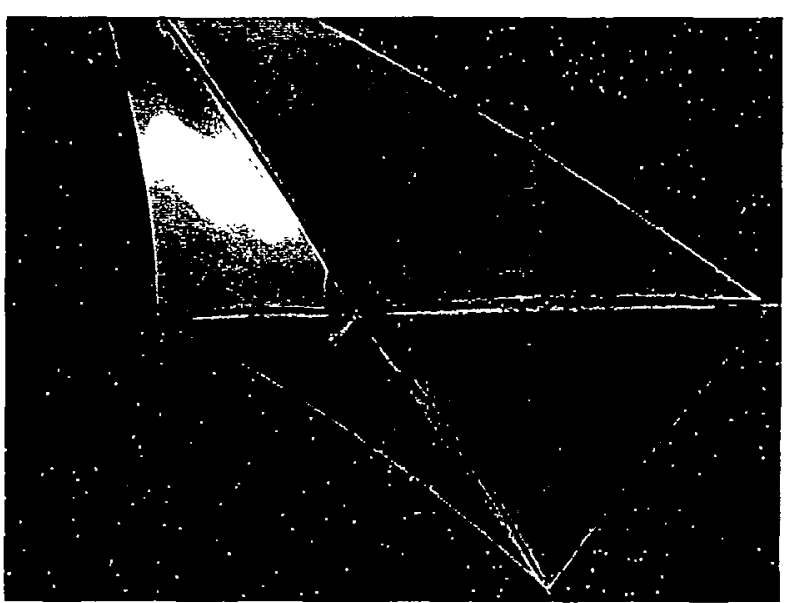

Figure 2. Square sail design with four-quadrant membranes

\section{Experimental Model}

The experimental model used in this study consists of two triangular sail panels with edge length $10 \mathrm{~m}$, supported by a single inflatable boom of diameter $0.097 \mathrm{~m}$, as shown schematically in Fig. 3 and in Fig.4. The sail material is 1 -mil thick Kapton polyimide film, and the boom material is 6mil polyethylene. The boom is sealed at each end by a rigid cap $1.9 \mathrm{~cm}$ thick. The dimensions of the test article were determined from a constantthickness scaling analysis from the proposed Geostorm mission sail (Refs. 10-14). Air pressure for inflation is provided by a small-diameter line through the top end cap, while pressure measurement and emergency venting is achieved through a separate line at the bottom end cap. The boom may be folded into a cardboard packaging tube approximately $0.5 \mathrm{~m}$ long located at the hub of the sail when it is not deployed. A counterbalancing system is employed to offset gravity loads to the system. The primary counterbalance (support 1 ) is provided by a cable attached to the upper end cap. In addition, two optional lines (supports 2 and 3 ) provide a lowermagnitude vertical force at the midpoint of each sail to aid in controlling potential curling and sagging of the sail edges under gravity. 


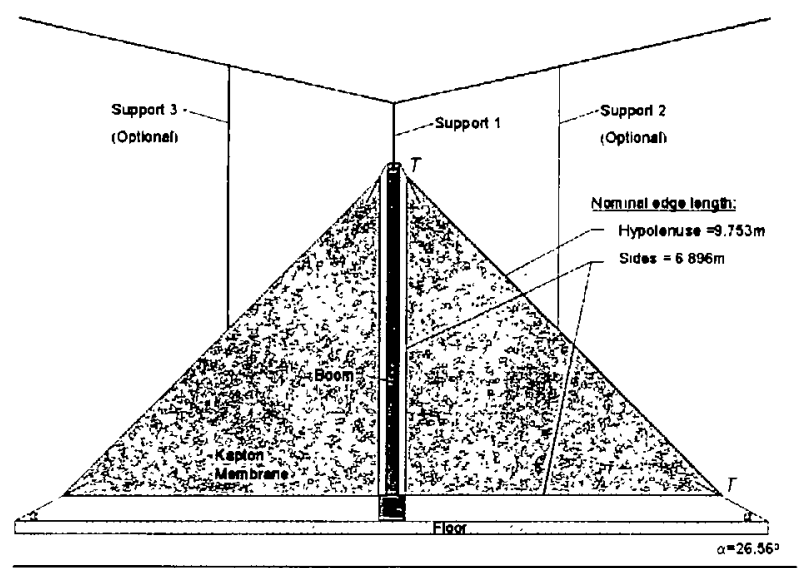

Figure 3. Schematic of two-quadrant, single boom vertical sail testbed

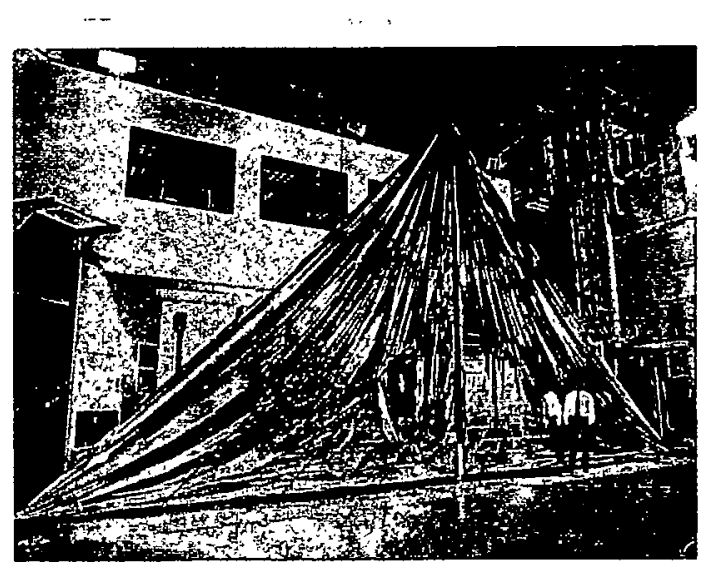

Figure 4. Experimental model

There are several items of direct instrumentation included in the sail system primarily for the purposes of determining loads at the system boundaries. An ATI Nano-25 six degree-of-freedom force/torque sensor is mounted at the lower end of the boom to provide measurements of loading at the hub of the structure. In addition, strain gage-based load cells are located in the counterbalance line at the top of the boom and in the grounding lines at the outside corners of the two triangular panels. The load cells will provide boundary input data for use in model/test correlation. Due to the nature of the structure, however, it is desirable that the majority of data should be obtained through indirect or noncontacting means. This will minimize the massloading and damping impact of items attached to the test article (Ref. 15).

Two methods of non-intrusive data acquisition have been used in this experiment. For static shape measurements, photogrammetry techniques are utilized with a dot-projection system. For dynamic measurements, retroreflective targets of $2.5 \mathrm{~cm}$ diameter are placed on a $1 \mathrm{~m}$ grid on the sails and boom, as shown in Figure 5. The targets are used in conjunction with a Polytec PSV-300 scanning laser vibrometer.

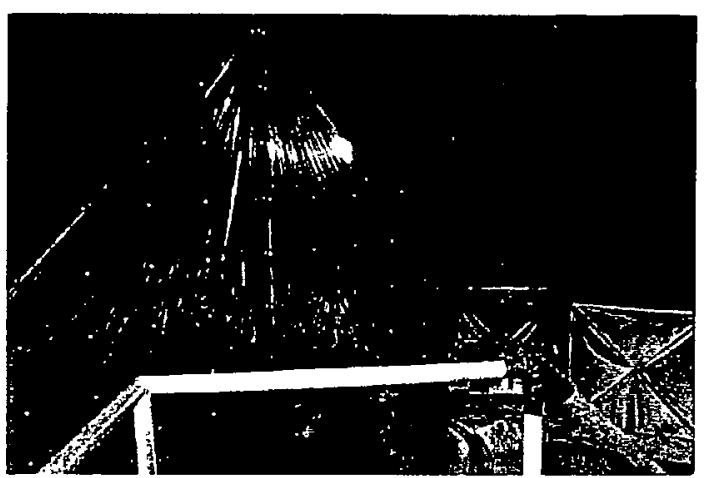

Figure 5. Sail model in $16 \mathrm{~m}$ vacuum chamber, reflective targets illuminated by flash

\section{Test Configuration}

The sail was installed in the 16 meter vacuum chamber of the Structural Dynamics Facility at LaRC. A tensioned Kevlar cable with two angled supporting cables was placed in the plane of the sail at the top of the chamber to provide support for the counterbalance. The vibrometer and other instrumentation systems were installed in the vacuum chamber control room. A glass viewport was installed in the wall of the chamber to allow for the operation of the laser in ambient atmospheric conditions (Figure 6). Data acquisition and control were performed using three systems: the vibrometer and dynamic excitation were controlled by the Polytec hardware/software package, while the ATI forcetorque sensor was read and controlled on an HP laptop running HyperTerminal and the load cells were read by a Zonic System 7000 A/D converter. Excitation was provided by a 3 lbf capacity (13.3 $\mathrm{N})$ Ling dynamic shaker mounted to the boom at a point $1.4 \mathrm{~m}$ from the lower end cap. The problems of shaker attachment on a flexible surface (and the resulting pathology of local deformation) were circumvented through the use of an extremely thin-gauge aluminum collar to which the shaker was mounted as shown in Figure 7 . The collar distributes the excitation force over a larger boom area. 


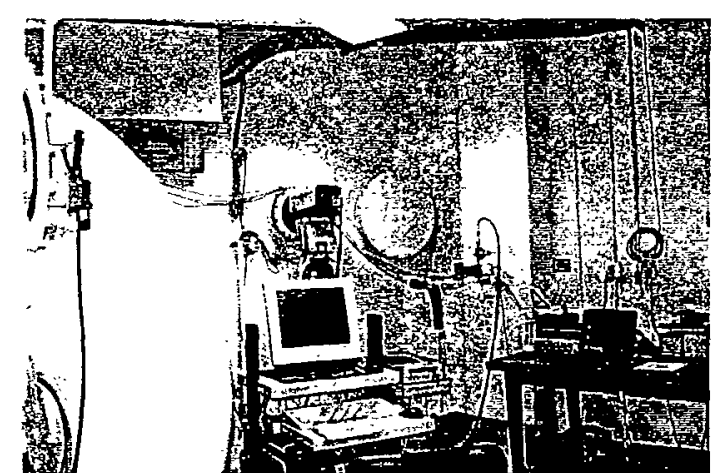

Figure 6. Vibrometer location at glass port

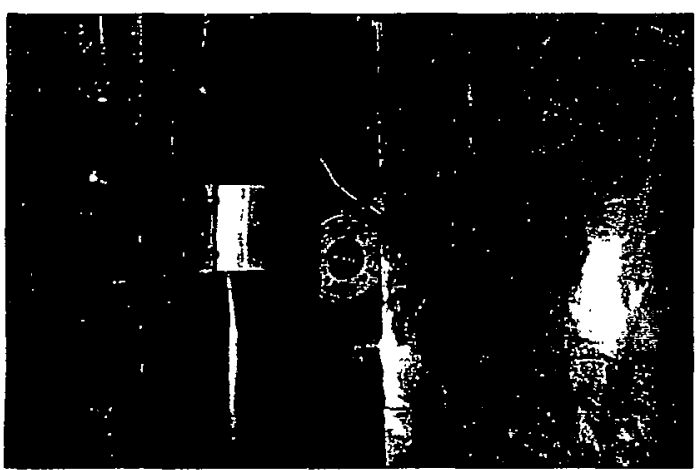

Figure 7. Shaker location on boom

First, testing was conducted in ambient conditions at atmospheric pressure. Then, the chamber was evacuated to a pressure level of 0.5 torr. In the ambient test case, the chamber doors were closed to minimize disturbance of the experiment by air currents.

\section{Results: Sail in Ambient Conditions}

Two forcing amplitudes were utilized in the ambient test, and the same level were used for the vacuum test to ensure a valid comparison. A pseudo-random input for excitation was used with a possible range between 0.1 and $50 \mathrm{~Hz}$. The low-amplitude excitation signal provided a maximum force level of $0.5 \mathrm{~N}$, while the highamplitude signal generated peak forcing of $2.0 \mathrm{~N}$. For all of the frequency response plots shown in this paper, the input point is the shaker location discussed above, and the response point is a point on the boom $5 \mathrm{~m}$ from the hub of the sail.
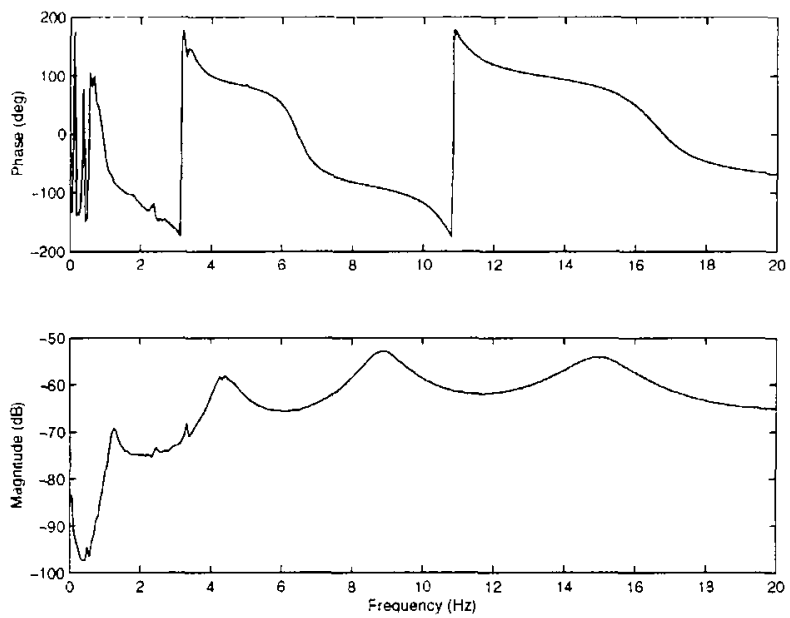

Figure 8. Frequency response function, boom/sail structure in ambient conditions, $F_{\max }=0.5 \mathrm{~N}$
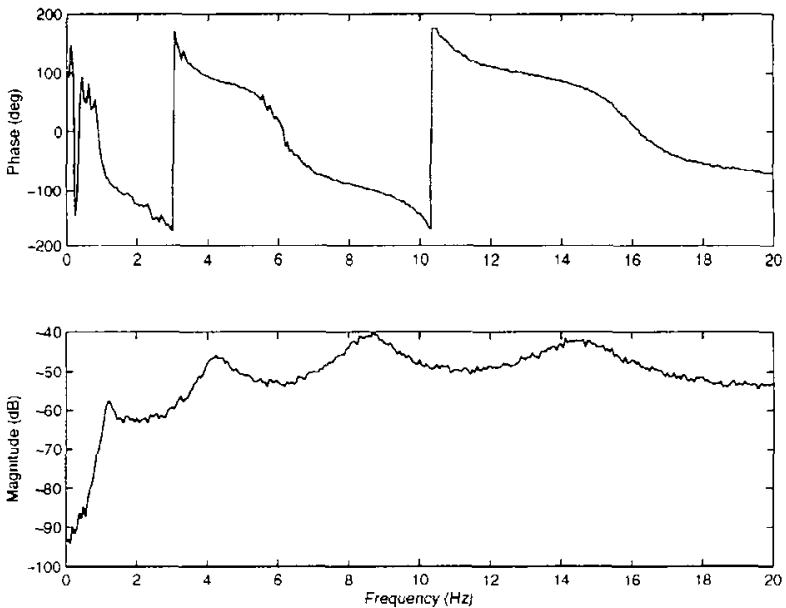

Figure 9. Frequency response function, boom/sail structure in ambient conditions, $F_{\max }=2.0 \mathrm{~N}$

The frequency response for the low-amplitude case, shown in Figure 8, displays a fairly smooth curve, indicating that sail response is not playing a large part in the response of the structure. In Figure 9, however, the effect of increasing the forcing amplitude may be seen in the numerous small peaks superimposed on the global response of the structure. Generally, in the ambient test results, the response of the structure is completely dominated by the motion of the boom, with the sail acting mostly as a damper.

Figures 10 through 13 show the responses for the four major peaks of the high-amplitude test case. In these plots, and in all of the mode shape plots to follow, red indicates positive velocity, green negative velocity, and black zero. It should be noted that the corner of the left sail is clipped due to angular limitations of the vibrometer when 
making measurements through the porthole of the vacuum chamber.

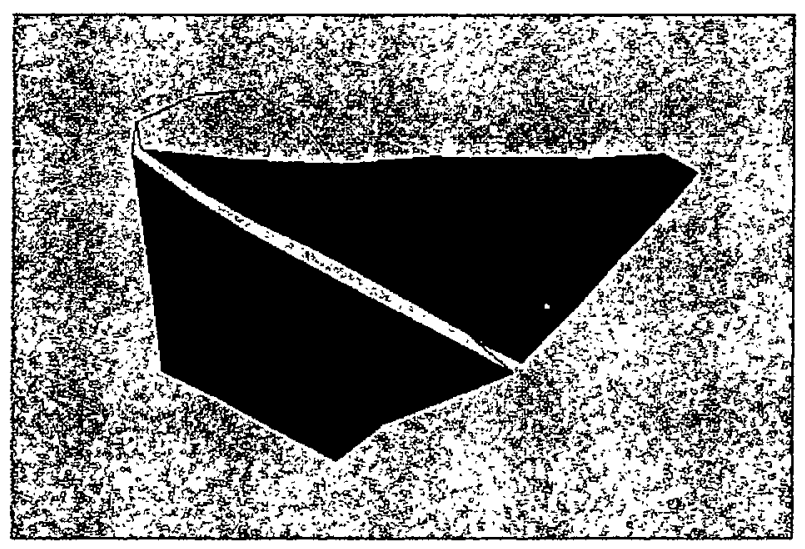

Figure 10. Mode shape for boom/sail structure in ambient conditions, $F_{\text {max }}=2.0 \mathrm{~N}$, peak $1 . f=1.2 \mathrm{~Hz}$

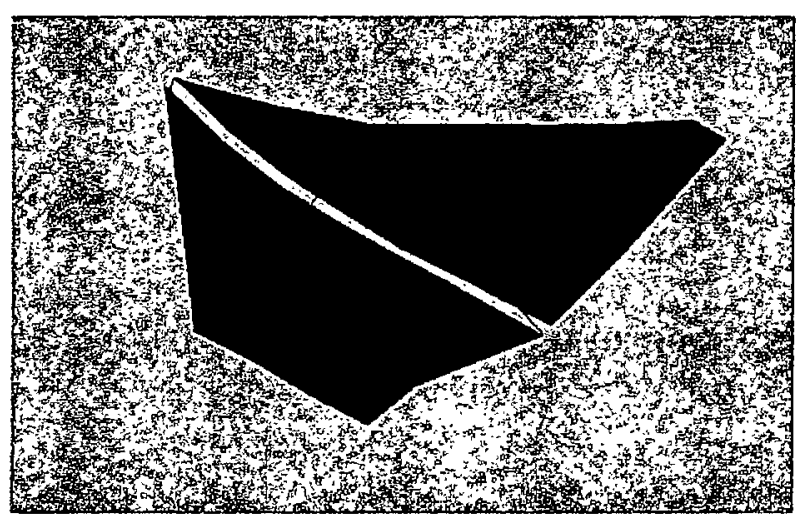

Figure 11. Mode shape for boom/sail structure in ambient conditions, $F_{\max }=2.0 \mathrm{~N}$, peak $2 . f=4.3 \mathrm{~Hz}$

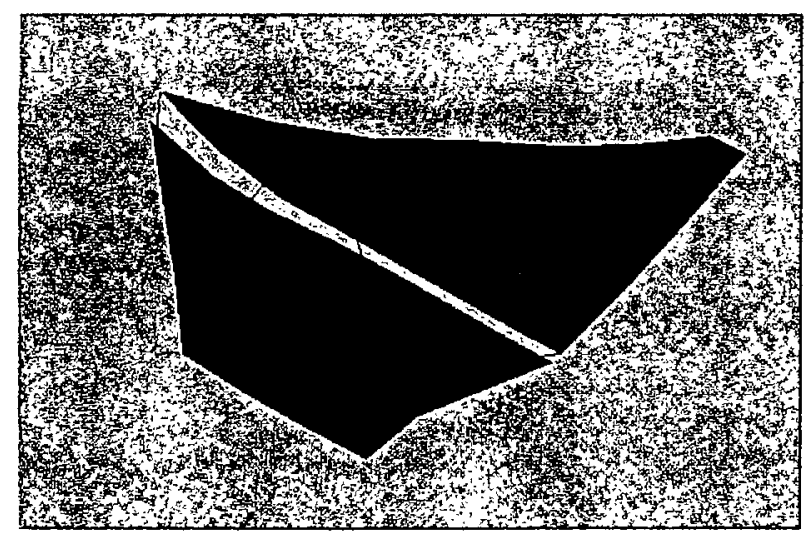

Figure 12. Mode shape for boom/sail structure in ambient conditions, $F_{\max }=2.0 \mathrm{~N}$, peak $3 . f=8.7 \mathrm{~Hz}$

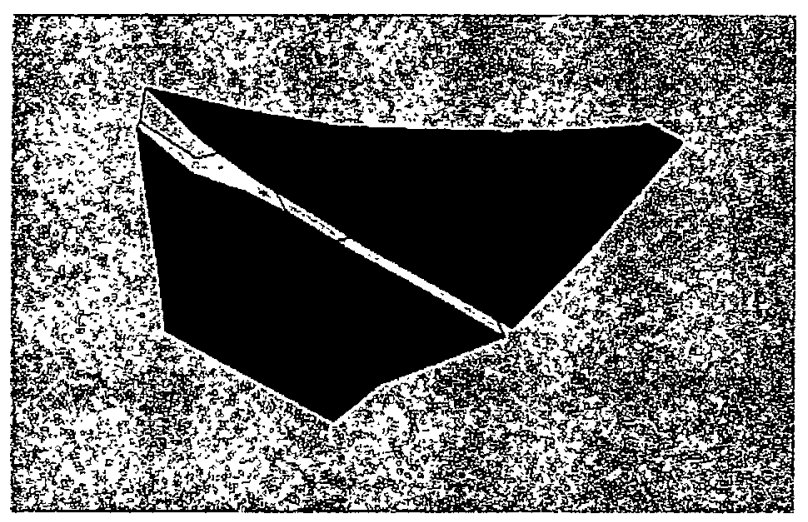

Figure 13. Mode shape for boom/sail structure in ambient conditions, $F_{\max }=2.0 \mathrm{~N}$, peak $4 . f=14.8$ $\mathrm{Hz}$

In addition, the system was tested in ambient conditions with the additional counterbalance lines providing an offset to gravity to the sail film, as described previously. The frequency response curves, seen in Figures 14 and 15, were quite similar to that of the one-counterbalance system shown in Figures 8 and 9.
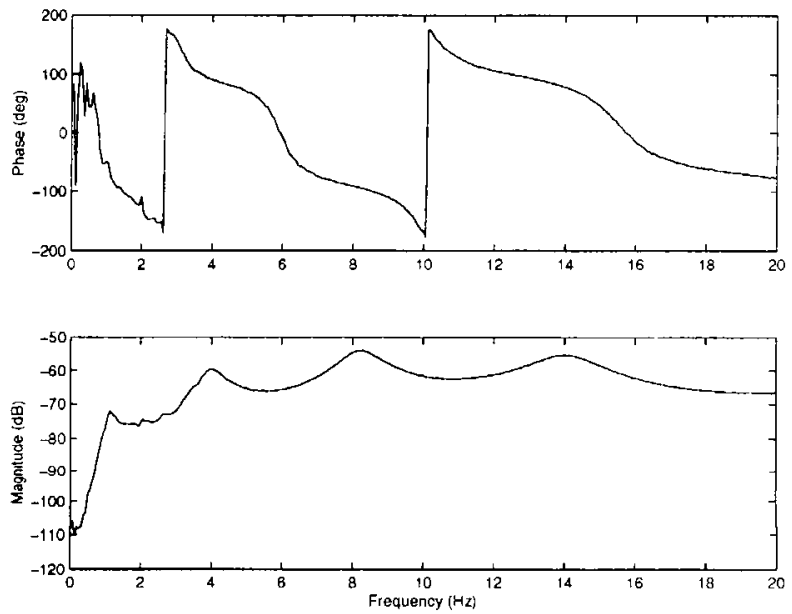

Figure 14. Frequency response function, boom/sail structure with added counterbalance in ambient conditions, $F_{\max }=0.5 \mathrm{~N}$

Figure 14 shows the frequency response for the low-amplitude $(0.5 \mathrm{~N})$ test case, while Figure 15 contains the same information for the largeamplitude $(2.0 \mathrm{~N})$ case. The resulting mode shapes will not be shown for the 3-counterbalance system, as they are almost indistinguishable from the 1-counterbalance results. 

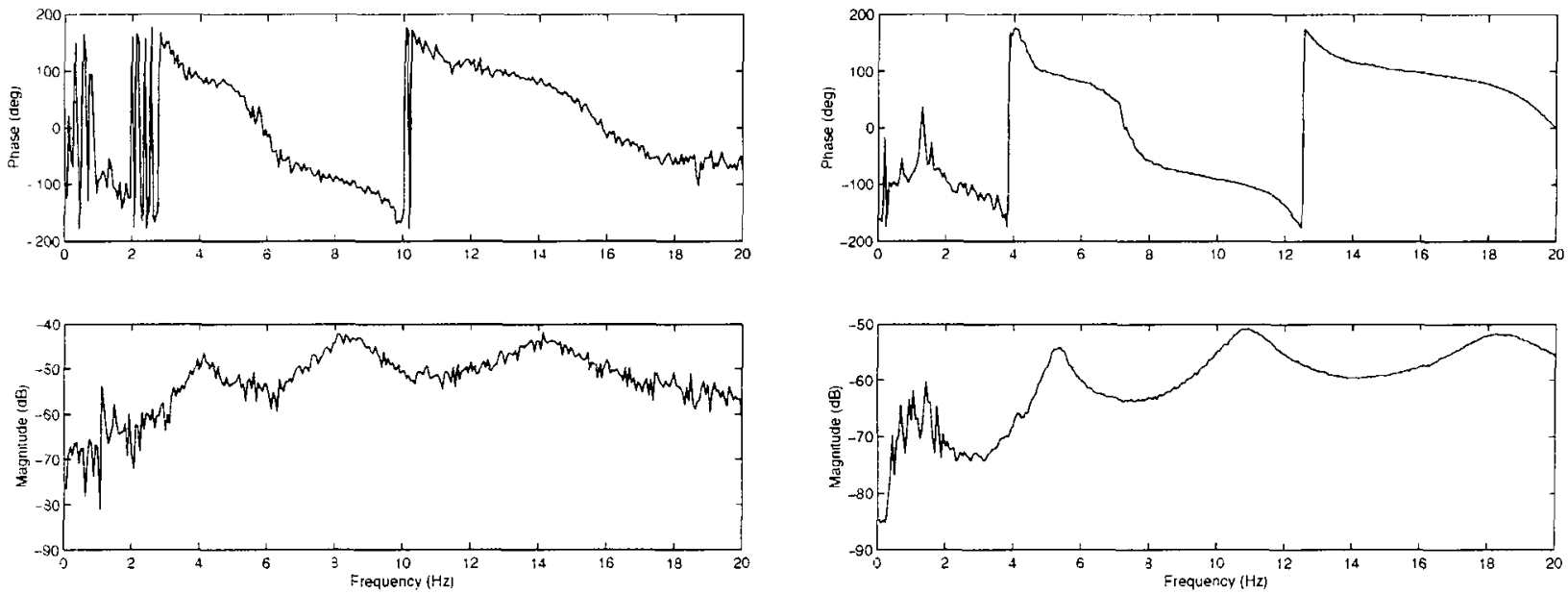

Figure 15. Frequency response function, boom/sail structure with added counterbalance in ambient conditions, $F_{\max }=2.0 \mathrm{~N}$

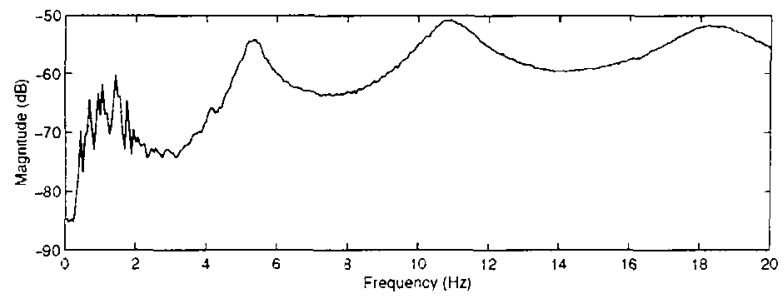

Figure 16. Frequency response function, boom/sail structure in vacuum conditions, $F_{\max }=0.5$ $\mathrm{N}$

A tabular comparison of the peak frequencies across test cases shows that the system in ambient conditions has stable resonant frequencies, although the presence of the extra counterbalances does provide a small frequency shift.

Table 1. Frequency comparison for boom modes, ambient test cases

\begin{tabular}{cccccc}
\hline TEST & $\begin{array}{c}\text { \# of } \\
\text { cables }\end{array}$ & $1^{\text {st }}(\mathrm{Hz})$ & $2^{\text {nd }}(\mathrm{Hz})$ & $3^{\text {rd }}(\mathrm{Hz})$ & $4^{\text {th }}(\mathrm{Hz})$ \\
\hline $0.5 \mathrm{~N}$ & 1 & 1.3 & 4.4 & 8.9 & 15.1 \\
$2.0 \mathrm{~N}$ & 1 & 1.2 & 4.3 & 8.7 & 14.8 \\
$0.5 \mathrm{~N}$ & 3 & 1.1 & 4.0 & 8.2 & 14.1 \\
$2.0 \mathrm{~N}$ & 3 & 1.1 & 4.1 & 8.3 & 14.1 \\
\hline
\end{tabular}

\section{Results: Sail in Vacuum Conditions}

The vacuum test was conducted with all parameters of the ambient test replicated. Results showed a significant difference in structural behavior given the presence or absence of air.
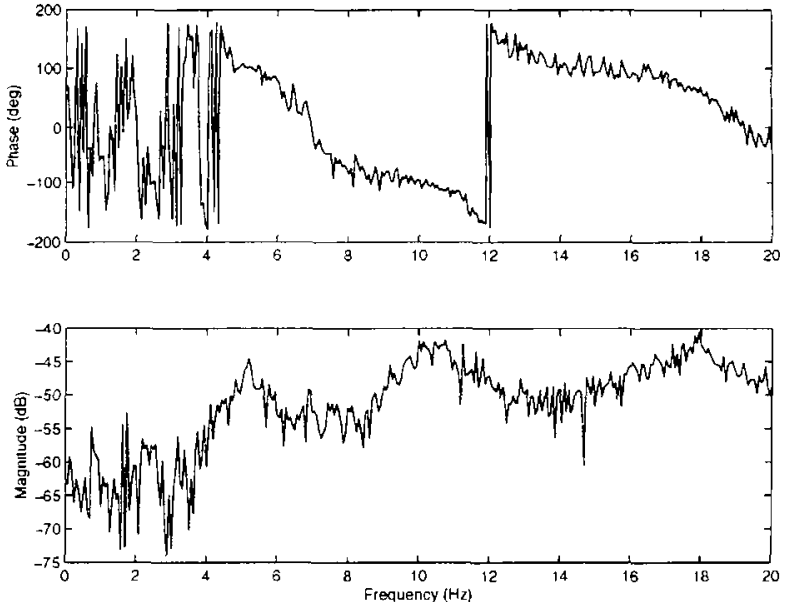

Figure 17. Frequency response function, boom/sail structure in vacuum conditions, $F_{\max }=2.0$ $\mathrm{N}$

The four response peaks which correspond to resonances of the boom appear in this series of data as well, although the behavior of the sail is more pronounced. As expected, the frequency locations of the boom-dominated peaks have shifted slightly higher than in the ambient case due to reduced air damping. The presence of identifiable peaks at very low frequencies corresponds to low-order resonant responses of the sail, as seen in Figures 22-24. 


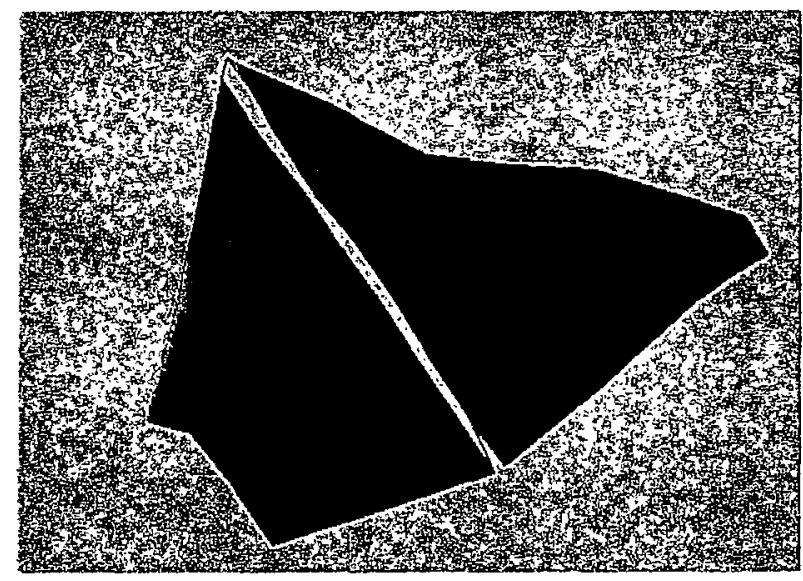

Figure 18. Mode shape for boom/sail structure in vacuum conditions, $F_{\max }=2.0 \mathrm{~N}$ : first bending resonance of boom at $1.8 \mathrm{~Hz}$

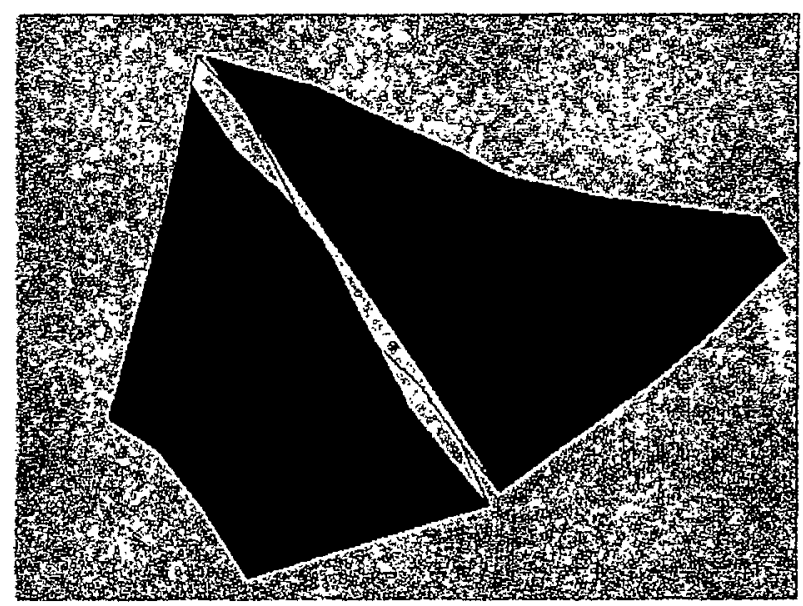

Figure 19. Mode shape for boom/sail structure in vacuum conditions, $F_{\max }=2.0 \mathrm{~N}$ : second bending resonance of boom at $5.0 \mathrm{~Hz}$

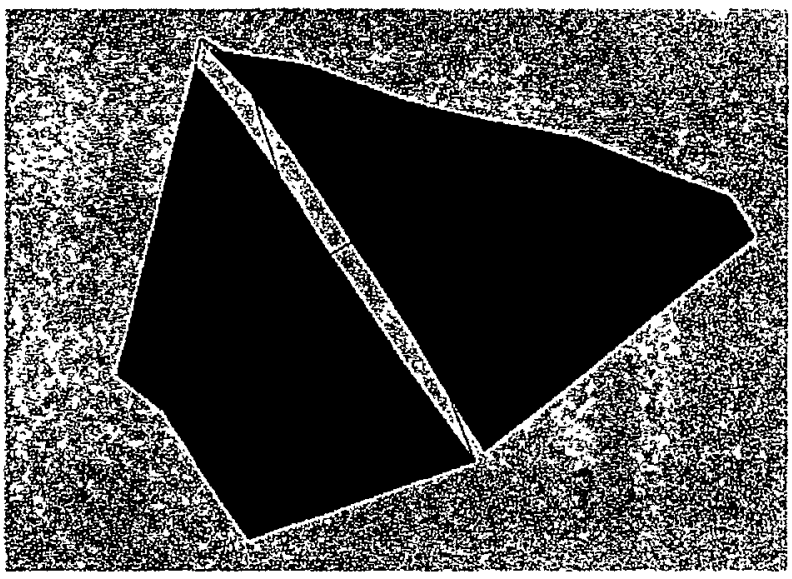

Figure 20. Mode shape for boom/sail structure in vacuum conditions, $F_{\max }=2.0 \mathrm{~N}$ : third bending resonance of boom at $10.4 \mathrm{~Hz}$

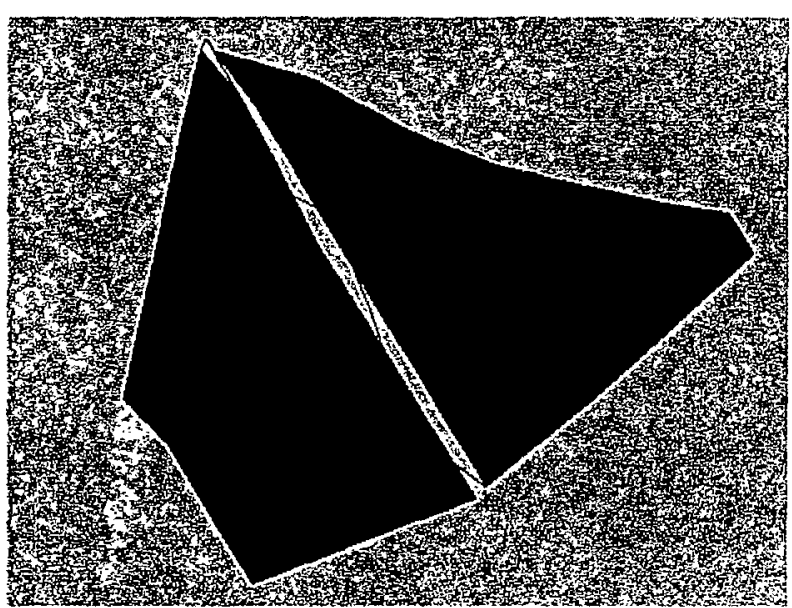

Figure 21. Mode shape for boom/sail structure in vacuum conditions, $F_{\max }=2.0 \mathrm{~N}$ : fourth bending resonance of boom at $17.8 \mathrm{~Hz}$ 


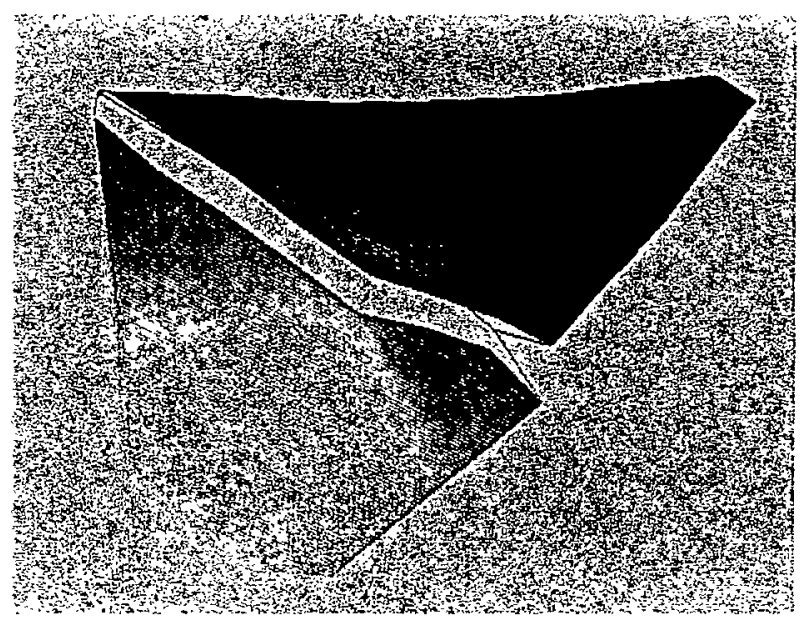

Figure 22. Mode shape for boom/sail structure in ambient conditions, $F_{\max }=2.0 \mathrm{~N}$, peak 1. $f=0.4 \mathrm{~Hz}$

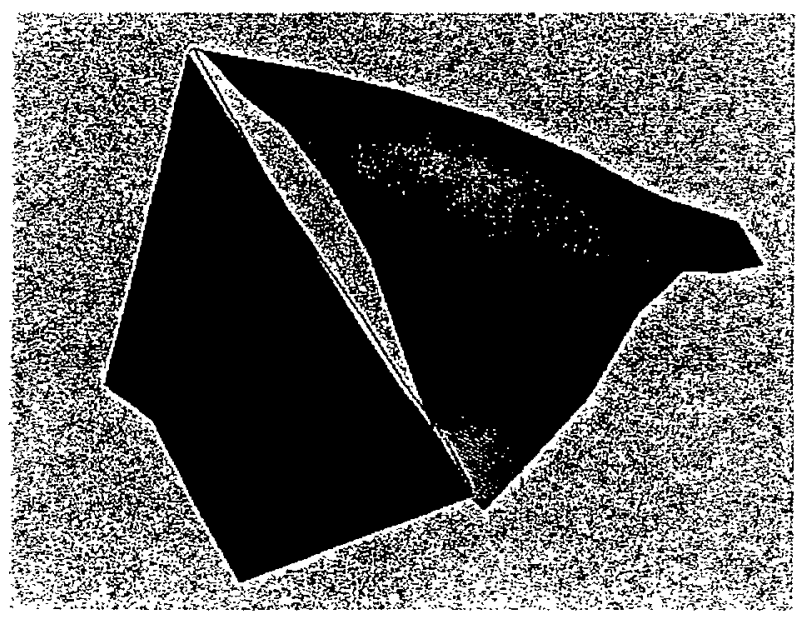

Figure 23. Mode shape for boom/sail structure in ambient conditions, $F_{\max }=2.0 \mathrm{~N}$, peak 2. $f=0.7 \mathrm{~Hz}$

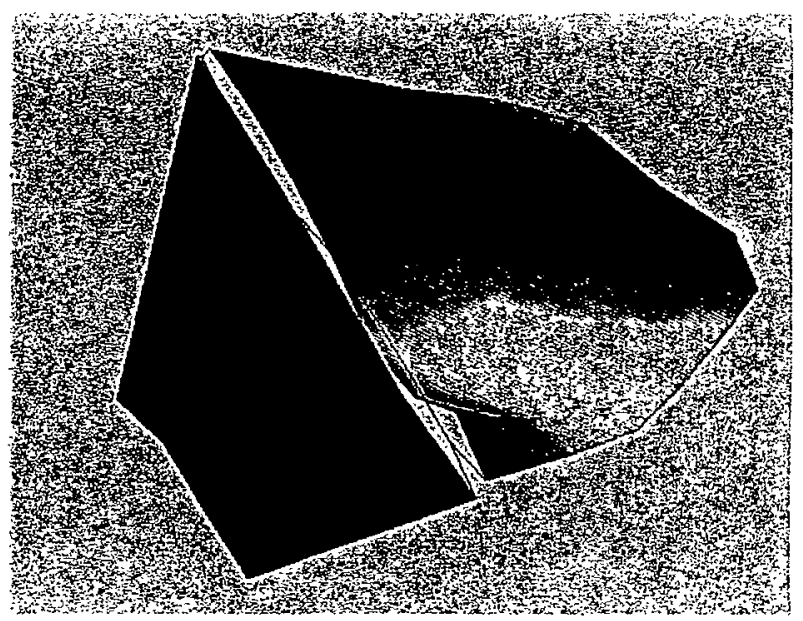

Figure 24. Mode shape for boom/sail structure in ambient conditions, $F_{\max }=2.0 \mathrm{~N}$, peak $3 . f=0.9 \mathrm{~Hz}$

It may be noted that the response of the left-hand sail is different from that on the right. It is believed that this is due to differences in construction between the two sails. The left-hand sail has heavier tape seams and a tape reinforcement running along the edge, while the right-hand sail has thinner seams and no reinforcement. Thus the left-hand sail is stiffer and heavier, leading to a lower-amplitude response with a different shape and/or phase. Updating the testbed with higher quality components should produce more symmetric responses.

The linearity (or lack thereof) of the system may be checked by performing a slow sine sweep up a frequency range and then down the same range. The presence of frequency shifts in the resonant peaks indicates nonlinearity in the system. Figures 25 and 26 show the sine sweep results for a point on the boom and on the sail respectively. It can be seen that the boom displays mostly linear behavior, while some minor shifts in frequency are visible on the sail response. This is to be expected given the more complex geometry of the wrinkled sail structure. 


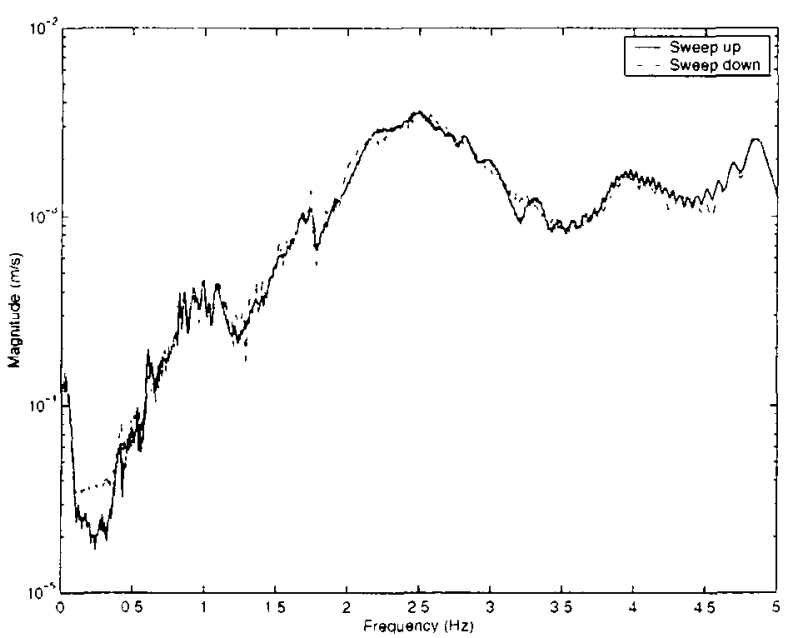

Figure 25. Sine sweep response for boom, $F_{\max }=1.0 \mathrm{~N}$

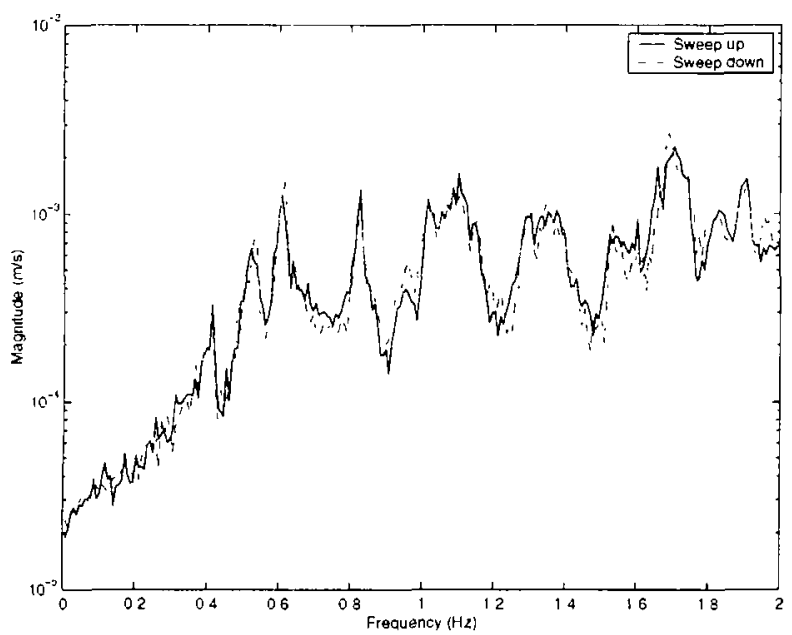

Figure 26. Sine sweep response for sail, $F_{\max }=1.0$ N

\section{Analysis}

Analytical models of the boom and of the overall structure were constructed in MSC/PATRAN, and analyses run in MSC/NASTRAN. For the sake of simplicity and computational efficiency, it was determined that beam elements would be used to model the inflated boom. The first step, then was to determine an effective modulus of elasticity $E$ which would take into account the stiffening effects of the air pressure. A model of the inflated boom was constructed using shell elements, and the model was subjected to a pressure load of 3447 $\mathrm{Pa}(0.5 \mathrm{psi})$ using a nonlinear static solution. The updated stiffness matrix was then used to restart a modal analysis. Using the first bending mode of the boom, and the analytical expression for the natural frequencies of a cantilevered beam with a tip mass, the effective $E$ for the pressurized boom may be calculated as $1.55 \times 10^{9} \mathrm{~Pa}$.

Given this information, the model of the boom/sail system may be run. A nonlinear static solution was run using the input loads at the sail corners and the top of the boom as measured by the load cells in the experiment. The relevant loads were approximately $18 \mathrm{~N}$ at the sail corners and $27 \mathrm{~N}$ at the top of the boom. Gravity loading was also included in the model. The resulting stress contour plot may be seen below in Figure 27.

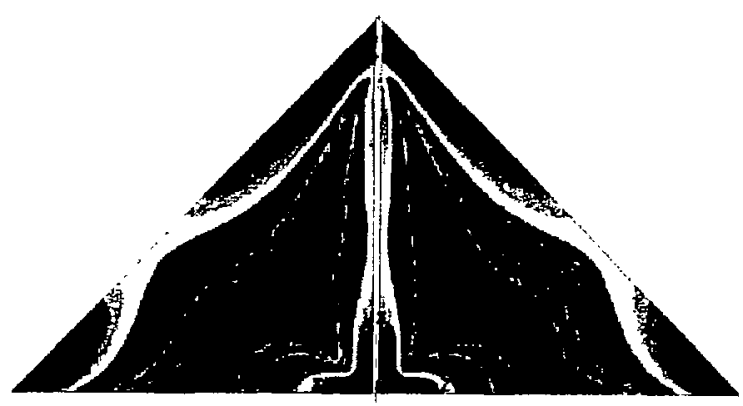

Figure 27. Stress contour plot for static pre-stress solution

Then, the dynamic solution for the system is run given the updated matrices from the static results. In Figure 28, the frequency response curve for a point on the boom 5 meters from the floor is shown. The first two dominant peaks may be qualitatively said to have good agreement, although there is a frequency shift between experiment and analysis. 


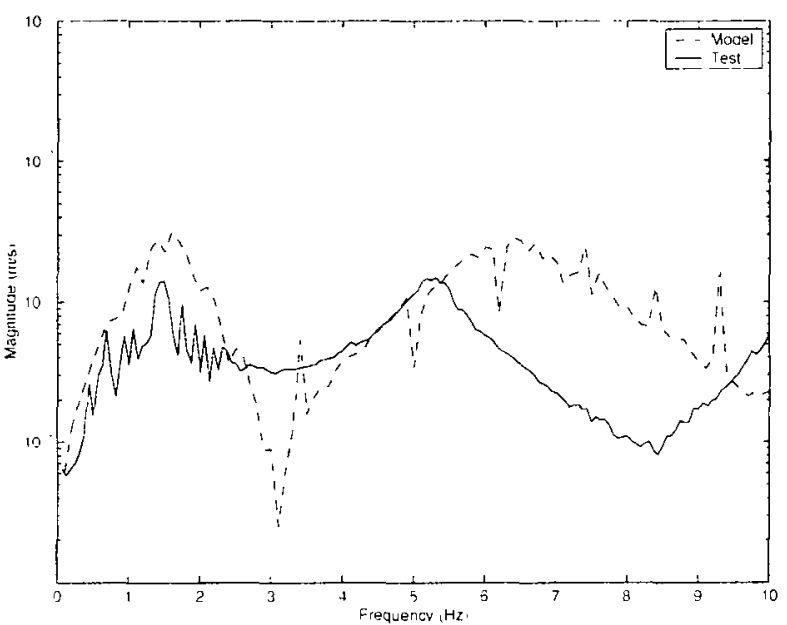

Figure 28. Comparison of model and experiment, point on boom $5 \mathrm{~m}$ from base. Dashed line indicates model, solid line experiment.

\section{Discussion}

From the results presented in the previous sections, the difficulties inherent in attempting to characterize this type of structure are clearly evident. While the responses dominated by the boom are fairly similar, substantial differences between the vacuum and ambient results can be seen for the behavior of the sail. Thus, for structures where the sail dynamics are relevant, testing in vacuum is a necessity.

Correlation between testing and analysis is also a problematic area. One factor which may contribute to the difference in responses for model and experiment is the presence of the loose cardboard packaging tube at the base of the boom which may have added some constraint to the experiment that was not present in the model. This constraint would be difficult to model accurately. Also, the cable counterbalance system, which was included in the model, is difficult to characterize well. Of course, the primary difficulty is that of the membrane itself in its out-of-plane dynamics. In addition, the low quality membranes exhibited highly nonlinear behavior due to wrinkling.

There are several future directions for the experiment. One involves the testing of various boom materials with the 2-quadrant sail and comparing the response characteristics both in deployment and in flexible body dynamics. As mentioned previously, a higher-quality seamless sail is scheduled to be tested as well. A rigidized boom will also be incorporated into the testbed.
These higher quality components should provide more deterministic dynamic response.

Future efforts in analysis will primarily be focused on improving the out-of-plane behavior of the thin shell elements. A different method for prestressing the structure is needed, and different codes such as ABAQUS or STAGS will be used. Also, the boundary constraints for the testbed need to be further refined.

\section{Summary}

A two-quadrant, 10 meter solar sail was tested dynamically both in ambient and vacuum conditions. While the ambient test results were dominated by the response of the boom, it was possible to find some low-order sail responses in vacuum. The frequencies at which the boomdominated peaks occurred were fairly consistent across the various test cases, with an increase in frequency occurring in vacuum due to the change in damping. Sine sweep testing in vacuum showed that while the boom responded in a linear manner, the sail did not. While the results of the analysis look promising for the global, boomdominated responses, the out-of-plane behavior of the sail is problematic and needs further attention.

\section{References}

1. Wright, J. L., Space Sailing. Fordon and Breach Science Publishers, Overseas Publishers Association, 1079 LH Amsterdam, the Netherlands, 1992.

2. Mclnnes, C. R. , Solar Sailing: Technology, Dynamics and Mission Applications. Springer Praxis series in space science and technology. Springer, London, UK, First edition, 1999. Published in association with Praxis Publishing, Chichester, UK, 1999.

3. Chmielewski, A. B., Moore, C. , and Howard, R., The Gossamer Initiative. IEEE paper 0-78035846-5/00, Jan. 2000.

4. West, J. L. and Derbes, B. Solar Sail Vehicle System Design for the Geostorm Warning Mission. AIAA-2000-5326. 
5. St. Clair, A. K.; St. Clair, T. L.; Slemp, W. S. Recent Advances in Polyimide Science and Technology. Weber, W.; Gupta, M. Editors, Society of Plastics Engineers, Poughkeepsie, NY, 16-36, 1987.

6. Watson, J. J., Static-Test Results for the Characterization of Inflatable Rigidizable Columns. AIAA Paper 2001-1269, $2^{\text {nd }}$ Gossamer Spacecraft Forum, Seattle, WA, April 2001.

7. Leipold, M., et. al. ODISSEE - a proposal for demonstration of a solar sail in Earth Orbit. Pasadena, CA, April 27-May 1 1998. International Academy of Astronautics. Presented at the IAA Third International Conference on Low-Cost Planetary Missions.

8. NGST $1 / 2$-scale Inflatable Sunshield Deployment. Final Report by ILC Dover and L'Garde, June 1998

9. Lienard, S., et. al., Dynamic Testing of a Subscale Sunshield for the Next Generation Space Telescope (NGST). AIAA Paper 2001$1268,2^{\text {nd }}$ Gossamer Spacecraft Forum, Seattle, WA, April 2001.

10. Adler, A. L.; Mikulas, M. M., and Hedgepeth, J. M., Static and Dynamic Analysis of Partially Wrinkled Membrane Structures. AIAA-2000-1810.

11. Greschik, G.; Mikulas, M. M., and Freeland, R. E., Scaling of Nonlinear Phenomena with Emphasis on Thin Film Deployable Structures. Symposium on Deployable Structures: Theory and Application, Cambridge, UK, September 1998.

12. Mikulas, M. M., Greschik, G., and Adler, A. Preliminary Design Study of a Square Solar Sail Architecture. Solar Sail TIM, GSFC, May 1, 2001.

13. Mikulas, M. M., and Adler, A. Wrinkling Study of a Solar Sail Quadrant Loaded with Corner Loads. Slides presented at JPL, March 13, 2001.

14. Murphey, T. W., and Mikulas, M. M., Nonlinear Effects of Material Wrinkles on the Stiffness of Thin Polymer Films. AIAA 99-1341, AIAA Collection of Technical Papers, Vol. 2, pp. 12271238 (1999).

15. Slade, K. N., Virgin, L. N., and Bayly, P. V. Extracting Information from Inter-Impact Intervals in a Mechanical Oscillator. Phys. Rev. E 56:3B, Sept. 1997, pp. 3705-3708. 